\title{
Is Imipramine Helpful in the Treatment of Cancer? A Case Presentation and Discussion of Possible Clinical Implications
}

\author{
Thomas Sauer ${ }^{1}$ and Undine E Lang*1 \\ University Psychiatric Clinics, University of Basel, Switzerland \\ Received: May 22, 2018; Published: May 29, 2018 \\ *Corresponding author: Undine E Lang, Universitäre Psychiatrische Kliniken (UPK), University of Basel, and Wilhelm Klein Str 374056 Basel, \\ Switzerland
}

\section{Introduction}

Lung cancer is the number one cause of cancer deaths in the world, with more than 1.3 million people dying annually. Lung cancer is divided into two major histopathological groups, i.e. nonsmall cell lung cancer and small cell lung cancer [1,2]. Small cell lung cancer is a very deadly subtype of lung cancer characterized by the rapid expansion and metastasis of small cells with neuroendocrine features. Patients are most commonly diagnosed with metastatic stage disease. Without treatment, they may only survive a few weeks to months after the initial diagnosis, but systemic chemotherapy improves the median survival to approach a year. Still, cure is not possible with currently employed therapies and there is no approved targeted therapy for small cell lung cancer despite numerous attempts and clinical trials [1,2]. The "repositioning" of an existing drug to treat a disorder other than the one for which it was originally approved is an example of how extremely large genetic and biological databases are changing the face of medicine [3]. In this context, the antidepressant imipramine has been discussed recently to be potentially effective in combating small cell lung cancer, according to a study in labaratory mice from researchers at the Stanford University School of Medicine [2]. Small-cell lung cancers account for only about 15 percent of all lung cancers, but however, the five-year survival for small-lung cancer is only 6 percent.

\section{Case}

We report here a case of a 56-year-old man with a history of smoking for 35 years, diabetes, alcohol abuse and an initial weight loss of $10 \mathrm{~kg}$ over several months in January 2012. A chest X-ray obtained in January 2012 revealed a large tumor in the lung. Thoracic computed tomography (CT) performed in February 2012 showed metastases in the liver and lymph nodes. Physical examinations, including neurological findings, revealed no particular abnormal ities. Laboratory examinations, including a blood gas analysis were within the normal limits except for the levels of glucose, hemoglobin A1c and. A biopsy of the tumor obtained using video-assisted thoracoscopy was performed in the middle of May 2012 in order to establish an exact diagnosis. The biopsy performed revealed the diagnoses of an adenocarcinoma. The findings of bronchoscopy revealed infiltration of CD8-positive with a prognosis of 6 months. The patient had progressed disease (Stage IIIB, T4N2M0) and received a combination chemotherapy consisting of cisplatin and etoposide with concurrent accelerated hyperfractionated radiotherapy starting in mid-January. However, the chemotherapy was discontinued because the patient refused radiotherapy. Afterwards, six cycles of chemotherapy were completed. In the psychiatric department the patient presented himself in January 2012 with a severe depressive episode (HAMD 24 points) with depressed mood, loss of activity, feelings of hopelessness, sleep disturbances, suicidality and weight loss and loss of appetite and energy. The depression was treated successfully with imipramine $150 \mathrm{mg}$ per day -as this drug had been described to help also with small cell lung cancer. Imipramine was established also as a maintenance therapy over the next 36 months. The metastasis in the lung was found to be regredient on thoracic CT performed at the end of May 2016, and the serum ProGRP level decreased to $10.2 \mathrm{pg} / \mathrm{mL}$. Also the metastasis in the liver and lymph nodes decreased. The patient is still alive ( 6 years later), which is not according to the initial survival prognosis of 6 months.

\section{Discussion}

In conclusion, we believe that imipramine might be potentially useful as an antidepressant and second-line therapy in patients with lung metastasis. Basic research studies in mice are suggesting that cisplatin-resistant tumors are still sensitive to imipramine treatment [2]. In our clinical case we found possible effects of imipramine in vivo in an extensive stage of lung cancer, in a fatal 
situation, where all other treatment options were refused and the prognosis was fatal. However, another possibility might be a spontaneous regression of the malignant disease which would be defined as a partial or complete, temporary or permanent disappearance without appropriate treatment for the disease [4,5]. However, this phenomenon is very rare and has been described as occurring once in 60.000 to 100.000 cancer patients [4,5]. Spontaneous regression of lung cancer is more rare than that of other solid tumors. An important aspect of future experiments will be to continue to investigate the signaling networks perturbed by these drugs in small cell lung cancer cells. We found that the Pi3k mtor pathway might be linked to depressive behavior in mice Ackermann et al. and in a clinical setting the mtor inhibtor everolimus changed psychopathological symptoms, i.e. cognitive and mood performance.

Therefore, antidepressants might evolve their actions far beyond the monoamine hypothesis influencing athways which are involved in cancer development and progression. However, the use of tricyclic antidepressants has been decreased over the years due to the development of modern sertotonine reuptake inhibitors with a far better side effect profile. Jahchan et al. searched the electronic portion of the Stanford medical record (dating back around year 2000) for patients with small lung cancer who received a tricyclic antidepressant drug and found less than 5, none of whom were on the drugs chronically [2]. Based on our clinical observation, we propose that imipramine might be a useful option in therapeutic refractory situations or as maintenance treatment after chemother- apy in small cell lung cancer. Our observation of an increased survival in this patient possibly linked to imipramine treatment might suggest this drug also in off label use in patients suffering from other tumors, including glioma, colorectal cancer and retinoblastoma, which has been suggested at least by epidemiological studies $[6,7]$.

\section{References}

1. Neal JW, Gubens MA, Wakelee HA (2011) Current management of small cell lung cancer. Clin Chest Med 232: 853-863.

2. Jahchan NS, Dudley JT, Mazur PK, Flores N, Yang D, et al. (2013) A drug repositioning approach identifies tricyclic antidepressants as inhibitors of small cell lung cancer and other neuroendocrine tumors. Cancer Discov 3(12): 1364-1377.

3. Wang J, Byers LA (2013) Teaching an Old Dog New Tricks: Drug Repositioning in Small Cell Lung Cancer. Cancer Discov 3(12): 13331335.

4. Everson TC, Cole WH (1959) Spontaneous regression of malignant disease. J Am Med Assoc 169: 1758-1759.

5. Cole WH (1981) Efforts to explain spontaneous regression of cancer. J Surg Oncol 17: 201-209.

6. Walker AJ, Card T, Bates TE, Muir K (2011) Tricyclic antidepressants and the incidence of certain cancers: a study using the GPRD. British journal of cancer 104(1): 193-197.

7. McEvoy J, Flores Otero J, Zhang J, Nemeth K, Brennan R, et al. (2011) Coexpression of normally incompatible developmental pathways in retinoblastoma genesis. Cancer Cell 20(2): 260-275.
This work is licensed under Creative Commons Attribution 4.0 License

Submission Link: https://biomedres.us/submit-manuscript.php

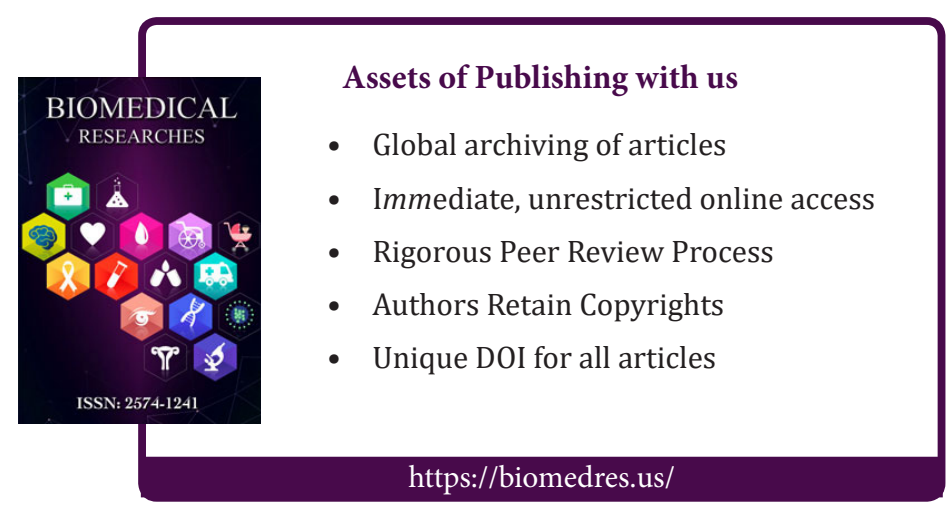

